\title{
An Overview of Software Safety Standards
}

\author{
J. Dennis Lawrence
}

This paper was prepared for submittal to the Second International Federation of Automatic Control (IFAC) Workshop on Safety and Reliability in Emerging Control Technologies

Daytona Beach, Florida

November 1-3, 1995

\section{October 1995}

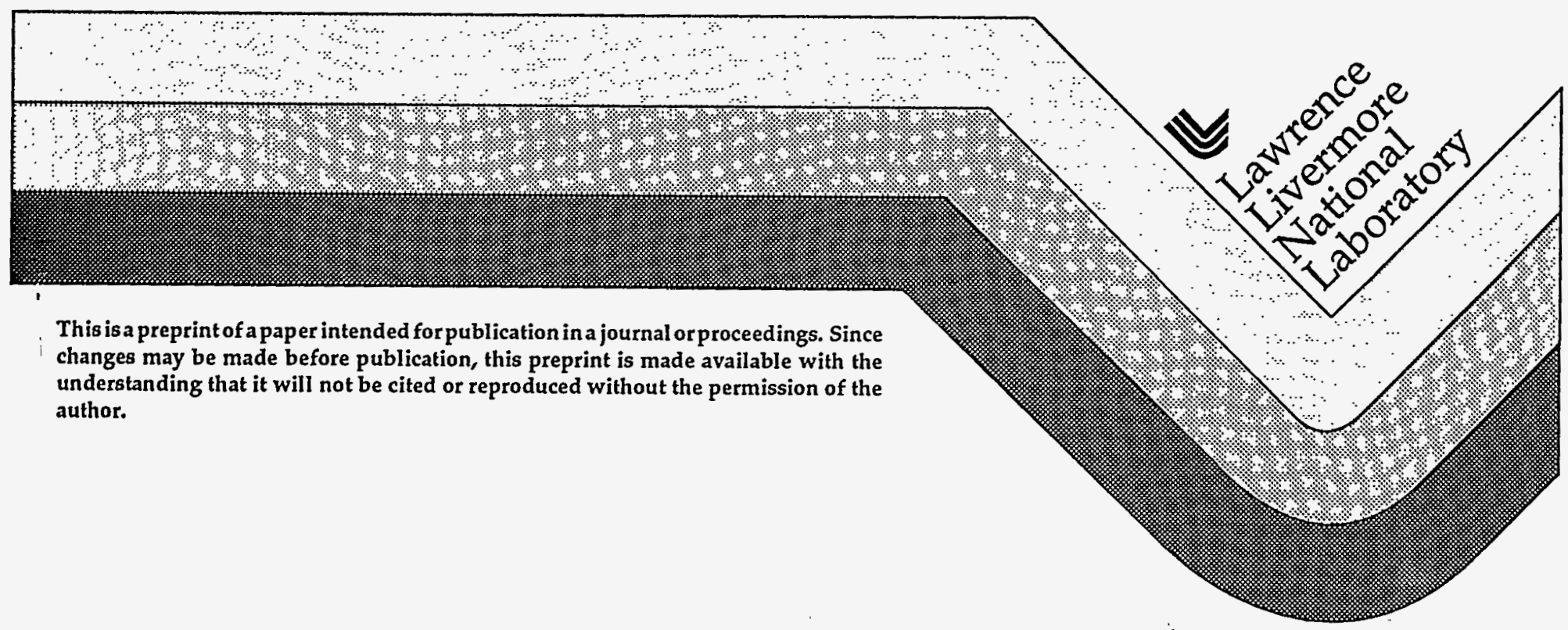




\section{Disclaimer}

This document was prepared as an account of work sponsored by an agency of the United States Government. Neither the United States Government nor the University of California, nor any of their employees, makes any warranty, express or implied, or assumes any legal liability or responsibility for the accuracy, completeness, or usefulness of any information, apparatus, product, or process disclosed, or represents that its use would not infringe privately owned rights. Reference herein to any specific commercial product, process, or service by trade name, trademark, manufacturer, or otherwise, does not necessarily constitute or imply its endorsement, recommendation, or favoring by the United States Government or the University of California. The views and opinions of authors expressed herein do not necessarily state or reflect those of the United States Government or the University of California.

This work was supported by the United States Nuclear Regulatory commission under a Memorandum of Understanding with the United States Department of Energy, and performed under the auspices of the U.S. Department of Energy by Lawrence Livermore National Laboratory under Contract W-7405-Eng-48. 


\title{
AN OVERVIEW OF SOFTWARE SAFETY STANDARDS*
}

\author{
J. Dennis Lawrence \\ University of California \\ Computer Safety \& Reliability Group \\ Fission Energy and Systems Safety Program \\ Lawrence Livermore National Laboratory \\ 7000 East Avenue, L-632 \\ Livermore, CA 94550 \\ e-mail address: lawrence2@llnl.gov
}

\begin{abstract}
The writing of standards for software safety is an increasingly important activity. This essay briefly describes the two primary standards-writing organizations, IEEE and IEC, and provides a discussion of some of the more interesting software safety standards.
\end{abstract}

Keywords: Computer software, safety, standards.

\section{INTRODUCTION}

The use of computers in safety-critical applications has increased considerably over the last several years, and is expected to continue at an increasing rate into the near future. Application areas include power plants, medical devices, aircraft, chemical plants, automobiles, and military weapons. Accompanying this increased usage is an increasing number of standards that can be used to help create safety-critical software systems.

Approximately three or four new standards have been appearing each year for most of the past decade, with several dozen now available. These are produced by a large variety of organizations, including professional societies, governments and individual companies.

This essay provides a brief survey of standards that relate directly to software safety. No claim is made for completeness; the author is not aware of all organizations writing such standards. Standards change as old versions are updated and new documents are written.

\section{STANDARDS-WRITING ORGANIZATIONS}

There are at least three dozen organizations writing standards that relate to software. Over a dozen of these have written software standards that directly relate to safety. Both of these numbers are likely to be low.

Standards organizations are affiliated with a variety of groups, from broad professional societies to individual companies. Table 1-provides a partial list of such organizations, divided into multi-disciplinary societies, governments, and industry sector societies. Individual companies that have written software safety standards are not included in this list.

The most important organizations are probably the Institute of Electrical and Electronics Engineers (IEEE) and the International Electrotechnical Commission (IEC). These are discussed next.

\subsection{IEEE}

IEEE is a large organization composed of societies that cover most areas of electrical and electronics engineering. One such society is the Computer Society, a portion of whose structure is outlined in Figure 1. 
The Computer Society is divided into technical activities, governed by the Technical Activities Board; standards activities, governed by the Standards Board; and other activities. One technical committee (TC) covers Software Engineering and one standards committee (SC) is the Software Engineering Standards Committee (SESC). These two committees work together to write standards on software engineering. As shown in Figure 1, standards activities report both to the Computer Society and to the IEEE Standards Board that oversees all IEEE standards work.

The Computer Society has written several dozen software engineering standards. One of these, IEEE 1228, Standard for Software Safety Plans, relates to software safety. In 1991, SESC began developing a long-range plan for software engineering standards. This plan (IEEE 1993), approved in December 1993, calls for additional work on software safety standards. A planning group, the Software Safety Planning Group (SSPG), was created in May 1995 to write a detailed plan for this topic.

Software engineering standards written by IEEE are generally submitted to standards-approving bodies for endorsement. In the United States, this is the American National Standards Institute (ANSI).

\section{Table 1 . Some Organizations Writing Software Safety Standards}

Multi-disciplinary Societies

\begin{tabular}{ll}
\hline BCS & British Computer Society \\
IEC & International Electrotechnical Commission \\
IEE & Institute of Electrical Engineers \\
IEEE & Institute of Electrical and Electronics \\
& Engineers
\end{tabular}

Government Bodies

\begin{tabular}{ll}
\hline CSA & Canadian Standards Association \\
DIN & Deutsches Institut fur Nomrung e.V. \\
DOD & United States Department of Defense \\
MOD & United Kingdom Ministry of Defence \\
NASA & $\begin{array}{l}\text { National Aeronautics and Space } \\
\text { Administration }\end{array}$
\end{tabular}

Industry Sector Societies

\begin{tabular}{ll}
\hline ANS & American Nuclear Society \\
ASME & $\begin{array}{l}\text { American Society of Mechanical } \\
\text { Engineers }\end{array}$ \\
EIA & Electronics Industry Association \\
ISA & Instrument Society of America \\
RTCA & $\begin{array}{l}\text { Requirements and Technical Concepts for } \\
\text { Aviation }\end{array}$ \\
UL & Underwriter's Laboratories \\
\hline
\end{tabular}

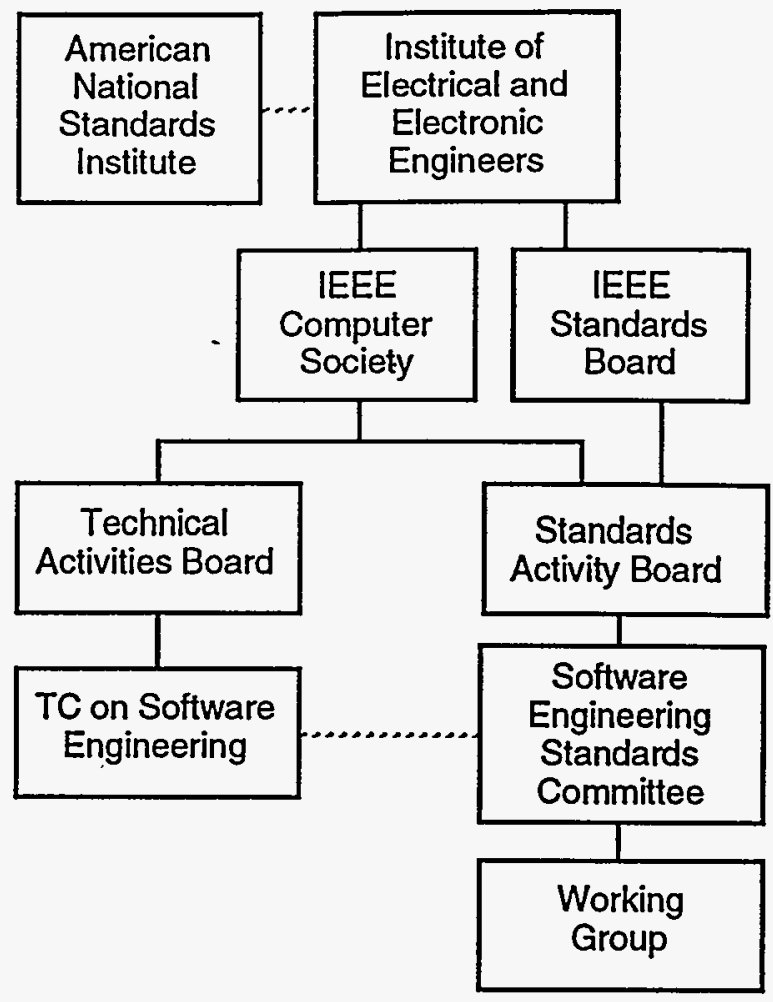

Figure 1. Structure for IEEE Software Engineering Standards Efforts

\subsection{IEC}

IEC is an organization composed of countries interested in standards activities in the areas of electricity, electronics and associated technologies. The technical work of writing standards is governed by the Committee of Action (Figure 2). Several of the 87 technical committees are involved in software standards, safety standards, and software safety standards.

TC 65 is responsible for industrial-process measurement and control; it has a subcommittee, SC $65 \mathrm{~A}$, which is responsible for systems aspects. This subcommittee has been working on safety standard IEC 1508 for many years.

IEC also contains industry-specific technical committees, some writing standards related to software safety. An example is TC 45, Nuclear instrumentation, and SC 45A, Reactor instrumentation, responsible for several standards relating to the safety of nuclear reactors when software is involved in reactor safety.

IEC works closely with the International Organization for Standards (ISO). The two organizations sponsor Joint Technical Committee 1, which works on matters of information technology, including software engineering. 


\section{EXAMPLES OF SOFTWARE SAFETY STANDARDS}

Table 2 lists a number of existing and proposed standards directly related to software safety. Since any aspect of software engineering may potentially affect safety, a great number of other standards exist that are indirectly related to safety. They are generally considered beyond the scope of this essay.

The remainder of this section consists of comments on a few standards listed in Table 2. Comments are based on the author's personal interests and opinions.

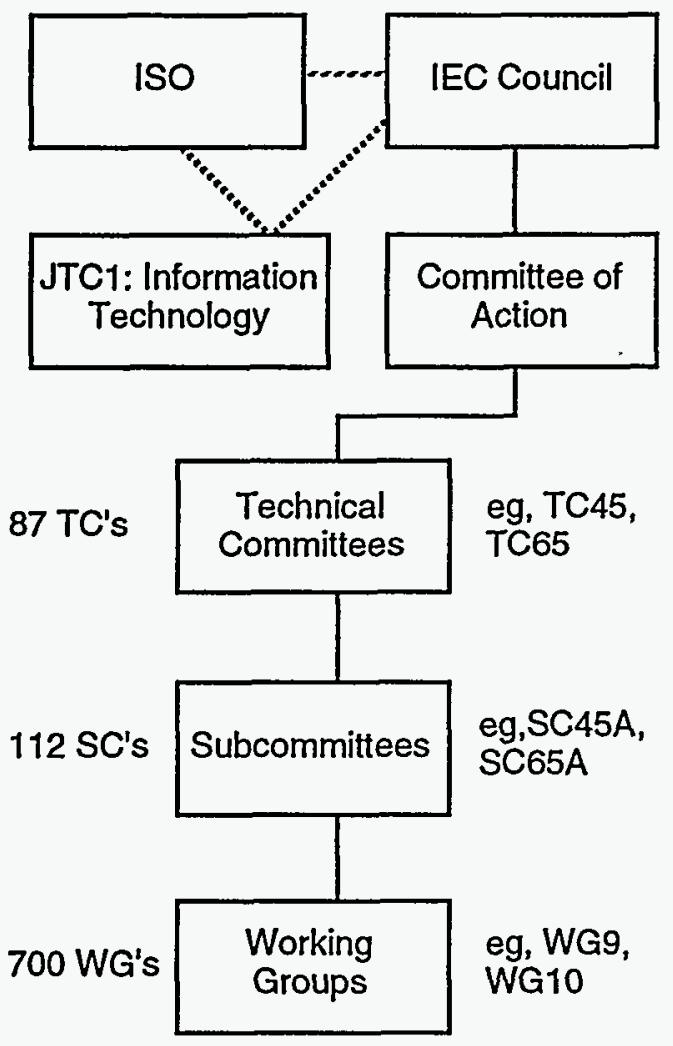

Figure 2. Structure for IEC Software Safety Standards Efforts

\subsection{AlAA R-013, Recommended Practice for Software Reliability}

Software reliability is not identical to safety, but is certainly a prerequisite. This standard can be used to create and operate a program for software reliability estimation. The purpose is to obtain reasonably precise, quantitative estimates of the reliability of software products.

\subsection{ASME NQA-1, Quality Assurance Requirements for Nuclear Facility Applications}

This standard has undergone many revisions since it was first issued in 1979. The latest version incorporates both NQA-1 and NQA-2, and covers most aspects of nuclear facility quality assurance. Of particular interest is Part II, subpart 2.7, "Quality Assurance Requirements for Computer Software for Nuclear Facility Applications."

NQA-1 contains a wealth of ideas that relate to quality assurance, and thus to facility safety. Much of this can be usefully transferred to other process-control applications where safety is involved.

\subsection{Mil Std 882C, System Safety Program Requirements}

Perhaps the most useful part of this standard is the concept of analyzing hazards by severity of potential consequences and probability of occurrence. These ideas can be combined into a table that can be used to assess risk; several examples are shown in Appendix A of the standard.

\subsection{IEC 880, Software for Computers in the Safety Systems of Nuclear Power Stations}

This standard describes principles and practices for the entire software development life cycle. Although directed at nuclear power stations, most of the concepts and specific details should apply equally to other process-control applications. Appendices include important recommendations on software development in safety-critical applications. A recent (1994) draft supplement discusses four additional topics: diversity against common mode failures, formal specification and design methods, automatic tools, and the use of pre-existing software.

\subsection{Draft IEC 1508, Functional Safety: Safety-Related Systems}

IEC SC 65A has been writing a standard on safety for some years. The result is a seven-part draft that covers much of system and software safety. The seven parts are: (1) General requirements, (2) requirements for electrical/electronic/programmable electronic systems, (3) software requirements, (4) definitions and abbreviations of terms, (5) guidelines on the application of part $1,(6)$ guidelines on the application of parts 2 and 3 , and (7) bibliography of techniques and measures.

\subsection{IEEE 1228, Standard for Software Safety Plans}

This standard provides a suggested table of contents for a software safety plan, and discusses the content of each section, including software safety management, software safety analyses, and post-development procedures. Writing a safety plan, and then following the plan during software development and operation, should increase the probability of a successful and safe proluct. 
Table 2. Examples of Software Safety Standards

\begin{tabular}{|c|c|c|c|}
\hline Source & Number & Title & Date \\
\hline AIAA & R-013 & Recommended Practice for Software Reliability & 1992 \\
\hline ASME & NQA-1 & Quality Assurance Program Requirements for Nuclear Facilities & 1994 \\
\hline ASTM & E 1246 & $\begin{array}{l}\text { Standard Practice for Reporting Reliability of Clinical Laboratory Computer } \\
\text { Systems }\end{array}$ & 1988 \\
\hline BCS & 81205 & $\begin{array}{l}\text { System Safety Instruction-System Safety Engineering in Software } \\
\text { Development }\end{array}$ & 1989 \\
\hline CSA & Q396.1.1 & $\begin{array}{l}\text { Quality Assurance Program for the Development of Software Used in Critical } \\
\text { Applications }\end{array}$ & 1989 \\
\hline $\operatorname{CSA}$ & Q396.1.2 & $\begin{array}{l}\text { Quality Assurance Program for Previously Developed Software Used in } \\
\text { Critical Applications }\end{array}$ & 1989 \\
\hline DIN & V/VDE 0801 & Principles for Computers in Safety-Related Systems (preliminary std) & 1989 \\
\hline DOD & $\begin{array}{l}\text { AFISC } \\
\text { SSH } 1-1\end{array}$ & Software System Safety & 1985 \\
\hline DOD & $\begin{array}{l}\text { Mil-Hdbk } \\
764\end{array}$ & System Safety Engineering Design Guide for Army Materiel & 1990 \\
\hline DOD & $882 \mathrm{C}$ & System Safety Program Requirements & 1993 \\
\hline EIA & SEB6-A & A Method for Software Safety Analysis & 1990 \\
\hline ESA & PSS-01-40 & $\begin{array}{l}\text { System Safety Requirements for ESA Space Systems and Associated } \\
\text { Equipment }\end{array}$ & 1988 \\
\hline IEC & 812 & $\begin{array}{l}\text { Analysis Techniques for System Reliability-Procedure for Failure Modes } \\
\text { and Effects Analysis (FMEA) }\end{array}$ & 1985 \\
\hline IEC & 880 & Software for Computers in the Safety Systems of Nuclear Power Stations & 1986 \\
\hline IEC & 987 & $\begin{array}{l}\text { Programmed Digital Computers Important to Safety for Nuclear Power } \\
\text { Stations }\end{array}$ & 1989 \\
\hline IEC & 1014 & Programmes for Reliability Growth & 1989 \\
\hline IEC & 1025 & Fault Tree Analysis & 1990 \\
\hline IEC & 1226 & $\begin{array}{l}\text { The Classification of Instrumentation and Control Systems Important to Safety } \\
\text { for Nuclear Power Plants }\end{array}$ & 1993 \\
\hline IEC & 1508 & Functional Safety: Safety-Related Systems (draft) & 1995 \\
\hline IEE & 5 & Software in Safety-Related Systems & 1989 \\
\hline IEEE & 7-4.3.2 & $\begin{array}{l}\text { Standard Criteria for Digital Computers in Safety Systems of Nuclear Power } \\
\text { Generating Stations }\end{array}$ & 1993 \\
\hline IEEE & 1228 & IEEE Standard for Software Safety Plans & 1994 \\
\hline ISA & SP 84 & Programmable Electronic Systems for Use in Safety Applications (draft) & 1994 \\
\hline MOD & $00-55$ & $\begin{array}{l}\text { The Procurement of Safety Critical Software in Defence Equipment Part 1: } \\
\text { Guidance }\end{array}$ & 1991 \\
\hline MOD & $00-56$ & $\begin{array}{l}\text { The Procurement of Safety Critical Software in Defence Equipment Part 2: } \\
\text { Requirements }\end{array}$ & 1991 \\
\hline NASA & 1740.13 & Software Safety Standard & 1994 \\
\hline RTCA & DO-178B & Software Considerations in Airborne Systems and Equipment Certification & 1992 \\
\hline UL & 1998 & Standard for Safety-Related Software (draft) & 1992 \\
\hline
\end{tabular}




\subsection{RTCA DOI78-B, Software Considerations in Airborne Systems and Equipment Certification}

This is the third version of a standard that provides guidance on determining whether software in aircraft meets the safety requirements of the aircraft. The increasing development of fly-by-wire aircraft increases the need to both develop software that (1) supports flight worthiness and (2) demonstrates that the

software supports flight worthiness. This standard can be of use for both goals.

\section{CONCLUSION}

Since an enormous number of organizations involved in software standards works around the world, the lack of coordination among them results in confusing and inconsistent results. In many ways, this has been a source of strength as multiple viewpoints emerge naturally and can be tested by groups attempting to use the standards. The author expects this to continue as more organizations become interested in writing standards for software in safety-critical applications.

Standards can be of considerable assistance to software developers, users and government regulatory bodies. Their use can provide a common vocabulary and common framework for expressing a software design and implementation, to the benefit of all parties. Standards are not a substitute for clear careful thinking, and no use of standards can guarantee safety. They are best thought of as one of many tools which can be used to help improve the safety properties of a software product.

\section{REFERENCES}

IEEE. 1993. Master Plan for Software Engineering Standards, Prepared by Software Engineering Standards Long-Range Planning Study Group, IEEE Software Engineering Standards Committee, December. 


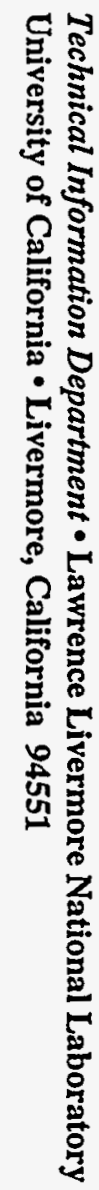

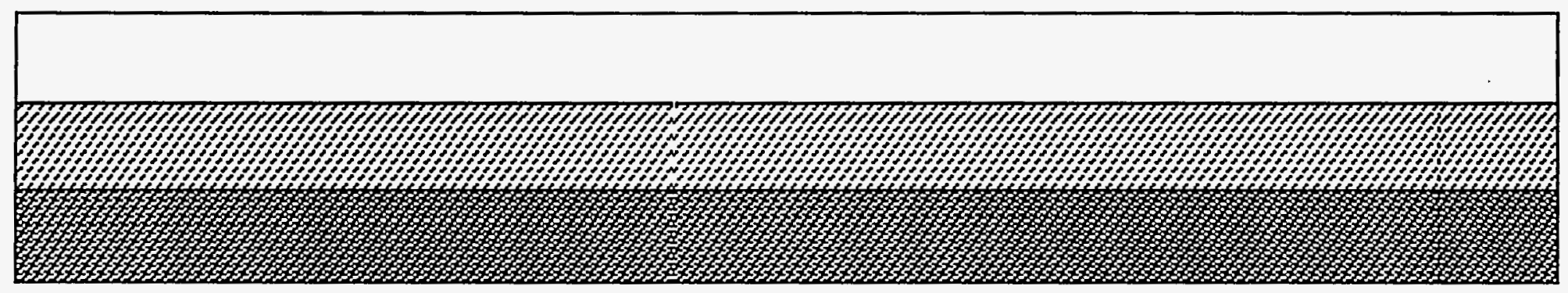

